ZOOLOGIA 27 (3): 445-450, June, 2010

doi: $10.1590 /$ S1984-46702010000300018

\title{
A new species of Psilocymbium with the description of the male and new records of $P$. lineatum at South Brazil (Araneae: Linyphiidae)
}

\author{
Everton Nei Lopes Rodrigues ${ }^{1,2} \&$ Ricardo Ott ${ }^{2}$
}

\author{
${ }^{1}$ Corresponding author. Programa de Pós-Graduação em Biologia Animal, Departamento de Zoologia, Instituto de \\ Biociências, Universidade Federal do Rio Grande do Sul. Avenida Bento Gonçalves 9500, Bloco IV, Prédio 43435, \\ 91501-970 Porto Alegre, Rio Grande do Sul, Brazil.E-mail: enlrodrigues@yahoo.com.br \\ 2 Museu de Ciências Naturais, Fundação Zoobotânica do Rio Grande do Sul. Rua Dr Salvador França 1427, \\ 90690-000 Porto Alegre, Rio Grande do Sul, Brazil. E-mail: rott@fzb.rs.gov.br
}

\begin{abstract}
The Neotropical genus Psilocymbium Millidge, 1991 can be recognized by the presence of a non-flagelliform, rigid and spiral shaped embolus, the absence of a cymbial basal excavation on the palp (males), and by having prolonged spermathecae on the epigynum and strong pedipalp setae (females). In this paper Psilocymbium antonina sp. nov., is described based on male and female specimens from the state of Paraná, southern Brazil. Psilocymbium antonina sp. nov. is diagnosed by the following combination of characters: prominent tibial apophysis with gauged distal projection, acute dorsal cymbial apex and acute cymbial proximal region of the palp (male); fertilization ducts distant from each other and the coiled copulatory ducts of the female epigynum. The male of $P$. lineatum (Millidge, 1991) is described and recorded for the first time in the states of Paraná and Rio Grande do Sul, Brazil.
\end{abstract}

KEY WORDS. Erigoninae; Neotropical; Paraná; Rio Grande do Sul; spider taxonomy.

Psilocymbium was proposed by MiLLIDGe (1991) and includes small spiders with body size less than $2.5 \mathrm{~mm}$. Known exclusively from South America, it contains six species: $P$. acanthodes Miller, 2007 from Argentina, P. defloccata (Keyserling, 1886) from Peru, $P$. incertum Millidge, 1991 and P. pilifrons Millidge, 1991 from Colombia, P. lineatum (Millidge, 1991) and the type species P. tuberosum Millidge, 1991 from Brazil (Platnick 2009).

Males of Psilocymbium can be recognized by a nonflagelliform rigid and spiral shaped embolus; they can be distinguished from males of Sphecozone O.P.-Cambridge, 1870 by the absence of a cymbial basal excavation and from males of Moyosi Miller, 2007 by the raised carapace or post-ocular hump. Females are recognized by the prolonged spermathecae and strong palpal setae (Millidge 1991, Miller 2007).

The examination of specimens from the collection of the Museu de Ciências Naturais da Fundação Zoobotânica do Rio Grande do Sul allowed the recognition and description of a new species of Psilocymbium from the state of Paraná, as well as the description of the male of $P$. lineatum, recorded for the first time in the states of Paraná and Rio Grande do Sul, Brazil; the body and genital morphology of both species are illustrated.

\section{MATERIAL AND METHODS}

Specimens are deposited at the collection of the Museu de Ciências Naturais, Fundação Zoobotânica do Rio Grande do Sul (MCN, Erica H. Buckup), Porto Alegre, Rio Grande do Sul, Brazil.
Specimens were illustrated using a Leica ${ }^{\circledR}$ MZ9.5 stereoscope with a camera lucida. Trichobothrium position on metatarsus I was calculated following Denss (1949). The descriptions and the terminology of palpal morphology follow MilLidge (1991) and Hormiga (2000). The tibial spine formula follows RoBERTs (1987). The study of reproductive structures of both male and female was performed by immersing the epigynum and the embolic division in lactic acid and/or clove oil for approximately 30 minutes until the internal structures could be perfectly visualized. For the expansion of structures the palp was immersed in $10 \%$ $\mathrm{KOH}$ for approximately two hours and after that immersed in filtered water. Measurements are expressed in millimeters. Abbreviations: (AME) anterior median eyes, (ALE) anterior lateral eyes, (PLE) posterior lateral eyes and (PME) posterior median eyes; (TmI) trichobothrium position on metatarsus I.

\section{TAXONOMY}

\section{Psilocymbium antonina sp. nov.}

Figs $1-9,18$

Types. Holotype male from Reserva Natural do Rio Cachoeira, Antonina, Paraná, Brazil, 21.IX.2007, E.S.S. Álvares leg., deposited in MCN 44807. Paratypes: all same data and locality as holotype, 1 female (MCN 46391), 3 females (MCN 44742) and 1 female (MCN 44800), same collector as holotype; 1 female (MCN 44786), R. Ott leg.; 1 male (MCN 45780) and 1 female (MCN 45781), I. Czisauskas leg. 

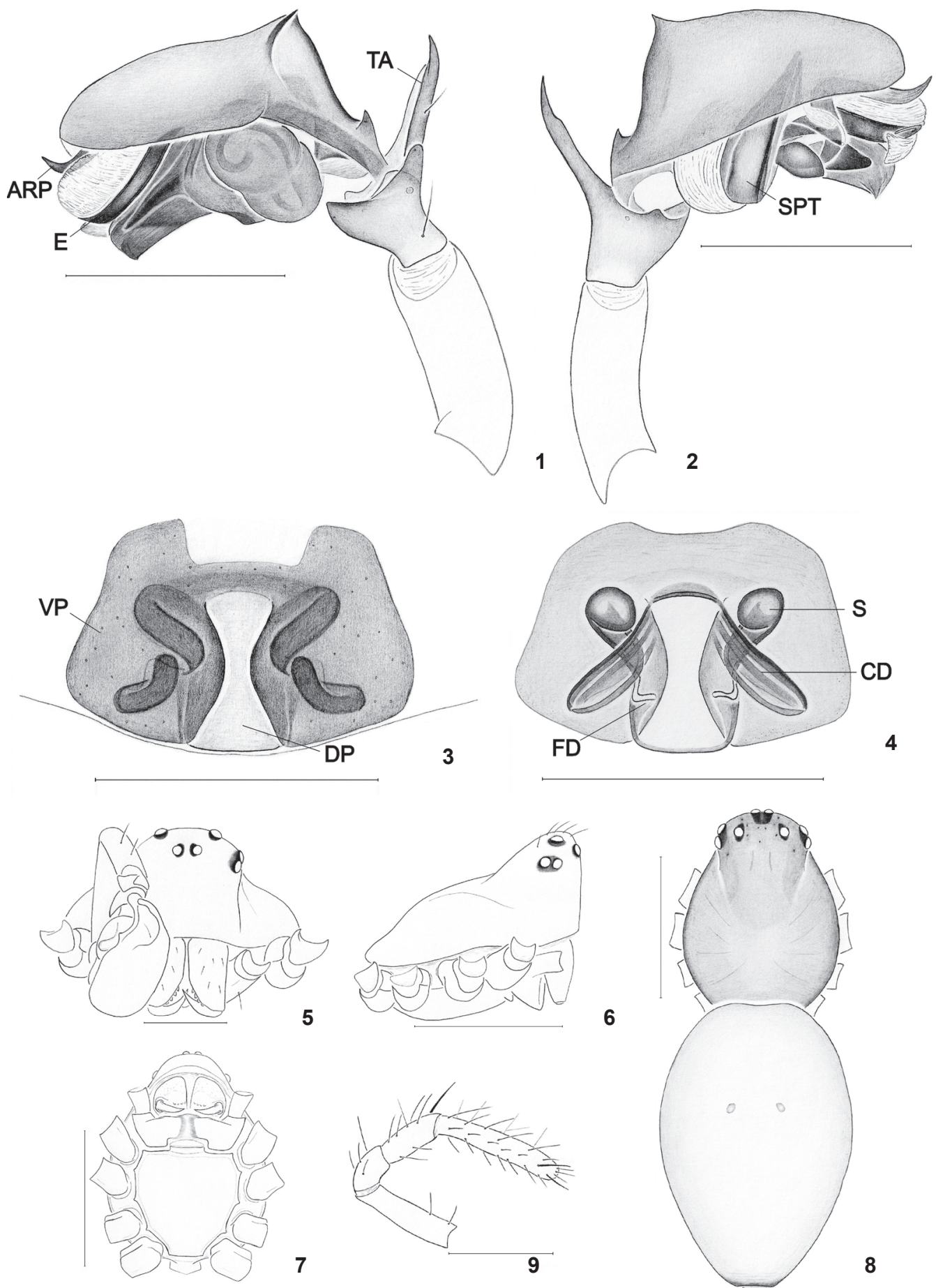

6

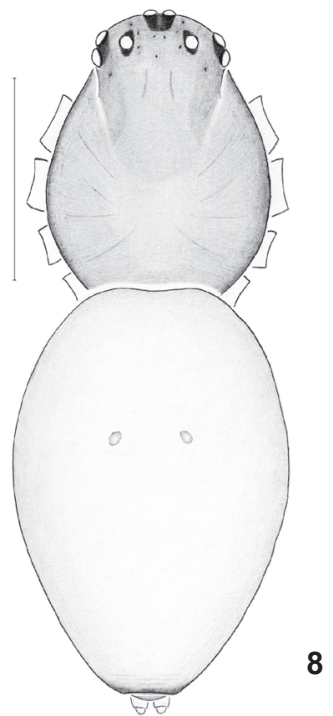

Figures 1-9. Psilocymbium antonina sp. nov. (1-2) Male palpus: (1) ectal view; (2) mesal view. (3-4) Female epygine: (3) ventral view, (4) dorsal view, cleared. (5-8) Male habitus: (5) frontal view of carapace; (6) lateral view; (7) ventral view, sternum detail; (8) habitus, dorsal view. (9) Female palp. (ARP) Anterior radical process, (CD) copulatory duct, (DP) dorsal plate, (DT) distal tooth of tibial apophysis, (E) embolus, (FD) fertilization duct, (TA) tibial apophysis, (S) spermatheca, (SPT) suprategulum, (ST) subtegulum, (T) tegulum, (VP) ventral plate. Scale bars: (1-4 and 9) 0,25 mm, (5-8) 0,5 mm. 
Diagnosis. The male palp of Psilocymbium antonina sp. nov. resembles that of $P$. tuberosum Millidge, 1991 (Millidge 1991: figs 785-787; MilLer 2007: figs 173a, b) by having an enlarged embolus with hooked tip (Figs 1 and 2), the anterior radical process projected and directed toward the cymbial apex, and a broad suprategulum (Fig. 2); it differs from the palp of $P$. tuberosum by the prominent tibial apophysis with gauged distal projection, acute dorsal cymbial apex and acute cymbial proximal region (Figs 1 and 2). The epigynum resembles that of P. tuberosum (Millidge 1991: figs 789-790; Miller 2007: figs $173 \mathrm{e}, 176 \mathrm{c})$ in having a dorsal plate that is longer than wide (Fig. 3), and differs in the fertilization ducts, more separated from each other, the coiled copulatory ducts and the round spermathecae (Fig. 4).

Description. Male (MCN 44807): Total length 1.65. Carapace length 0.67 , width 0.60 , height 0.37 . Clypeus height 0.25 . Chelicerae length 0.22 , width 0.12 . Sternum length 0.38 , width 0.40. Abdomen length 0.97, width 0.65, height 0.62. Leg formula IV/II/I/III. Leg lengths (I/II/III/IV): femur 0.62/0.63/0.53/ 0.68 ; patella $0.18 / 0.18 / 0.16 / 0.17$; tibia $0.62 / 0.60 / 0.41 / 0.58$; metatarsus $0.52 / 0.52 / 0.41 / 0.53$; tarsus $0.30 / 0.33 / 0.26 / 0.31$; total: 2.24/2.26/1.77/2.27. Coxa IV basis well appart from each other (0.17). Palp (femur, patella, tibia, cymbium): 0.40/0.23/ 0.23/0.34. Tm I 0.69. Metatarsus I-III with trichobothrium, IV absent. Tibial spine formula: 0-0-1-1. Eye diameters and interdistances: AME 0.03, ALE 0.03, PME 0.03, PLE 0.03; AMEALE 0.10, PME-PLE 0.06, AME-AME 0.02, PME-PME 0.12. Anterior eye row 0.31 , posterior row 0.32 . Small eyes with dark borders (Figs 5, 6 and 8). Clypeus remarkably high, not pubescent (Figs 5 and 6). Carapace anteriorly projected, yellowishbrown, setae present only at ocular area (Fig. 6). Chelicerae yellowish-brown, scarce frontal setae. Promargin with four very small teeth and retromargin with two teeth. Endites yellowishbrown. Sternum yellowish-brown with reddish-brown borders, pubescent, posteriorly truncated, wider as long (Fig. 7). Coxa yellowish-brown, III slightly smaller. Legs brown, femura distally and whole patella and tibia with dark-brown pigmentation. Abdomen longer than wide, oval, longitudinal stripe absent, yellowish-white dorsal and ventral portions, pigmentation around spinnerets, remarkably pubescent (Fig. 8). Spinnerets yellowish-brown. Colulus well developed. Palp femur with basal tubercle. Embolic membrane close to apex of embolus on mesal view, suprategulum with sharp apex and below cymbial margin, strong and elongated patella (Figs 1 and 2).

Female (MCN 46391): Total length 1.77. Carapace length 0.67 , width 0.57 , height 0.22 . Clypeus height 0.15 . Chelicerae length 0.20 , width 0.10 . Sternum length 0.38 , width 0.40 . Abdomen length 1.12 , width 0.72 , height 0.65 . Leg formula IV/ II/I/III. Leg lengths (I/II/III/IV): femur 0.62/0.66/0.52/0.70; patella $0.18 / 0.18 / 0.18 / 0.18$; tibia $0.55 / 0.56 / 0.35 / 0.56$; metatarsus $0.50 / 0.50 / 0.38 / 0.52$; tarsus $0.33 / 0.35 / 0.27 / 0.32$; total: $2.18 /$ 2.25/1.70/2.28. Coxa IV very distant (0.20). Palp (femur, patella, tibia, tarsus): 0.18/0.11/0.13/0.22. Palpal tibia and tarsus with macrosetas (Fig. 9). Tm I 0.67. Metatarsus I-III with trichobothrium. The tibial spine formula: 1-1-1-1. Eye diameters and interdistances: AME 0.02, ALE 0.05, PME 0.05, PLE 0.05; AME-ALE 0.06, PME-PLE 0.05, AME-AME 0.02, PME-PME 0.06 . Anterior eye row 0.25 , posterior row 0.27 . Eyes as in male. Clypeus high, not pubescent. Cephalotorax yellowish-brown with pale medial area, not pubescent. Chelicerae yellowishbrown, frontally pubescent. Promargin with four teeth and retromargin with two teeth. Endites yellowish. Sternum yellowish with brown borders, pubescent, truncated, wider than long. Coxa yellowish, III slightly smaller. Legs brown, femura distally and patella and tibia dark red-brown. Abdomen longer than wide, oval, without black longitudinal stripe, white-yellowish dorsal and ventral portions; pigmentation around spinnerets, remarkably pubescent. Colulus as in male. Epigynum with long copulatory ducts, short fertilization ducts, spermathecae at median-anterior position, rounded (Fig. 4).

Additional material examined. Brazil, Paraná: Antonina (Reserva Natural do Rio Cachoeira), 1 female, 21.IX.2007, pitfall-trap leg. (MCN 45805).

Distribution. Only known from the type locality in Paraná, Brazil.

Etymology. The species epithet, in apposition, refers to the type locality.

Natural history. Collected with beating tray at bush and tree vegetational strata and in litter with pitfall-traps, all at Atlantic Forest areas.

\section{Psilocymbium lineatum (Millidge, 1991) Figs 10-18}

Gilvonanus lineatus Millidge, 1991: 132, figs 533-534 (Holotype female from Campo das Antas, Teresópolis, Rio de Janeiro, Brazil, deposited at AMNH, not examined); Platnick, 1993: $279 ; 2009$.

Psilocymbium lineatum: Miller, 2007: 229, fig. 176d.

Diagnosis. The male palp of Psilocymbium lineatum (Millidge, 1991) (Figs 10 and 11) resembles that of $P$. acanthodes Miller, 2007 (see MiLLER 2007: 172a, b, 174a-f), in having prolonged embolus with distal loop and a distal tooth at the tibial apophysis (Fig. 10); it differs from the male palp of the latter by having a dorsal projection at the base of cymbium with additional spines at the dorsal portion (Figs 10 and 11) and tibial apophysis straight, bearing a poorly developed distal tooth. The epigynum differs from that of $P$. acanthodes (MilLer 2007: 172c, h; 176b) by lacking the anterior process on the ventral epyginal plate (Fig. 16) and by the kidney-shaped, curved spermathecae (Fig. 17).

Description. Male (MCN 46392): Total length 1.40. Carapace length 0.65 , width 0.47 , height 0.27 . Clypeus height 0.15 . Chelicerae length 0.17 , width 0.10 . Sternum length 0.30 , width 0.33 . Abdomen length 0.80 , width 0.52 , height 0.55 . Leg formula IV/I/II/III. Leg lengths (I/II/III/IV): femur 0.38/0.38/0.31/ 

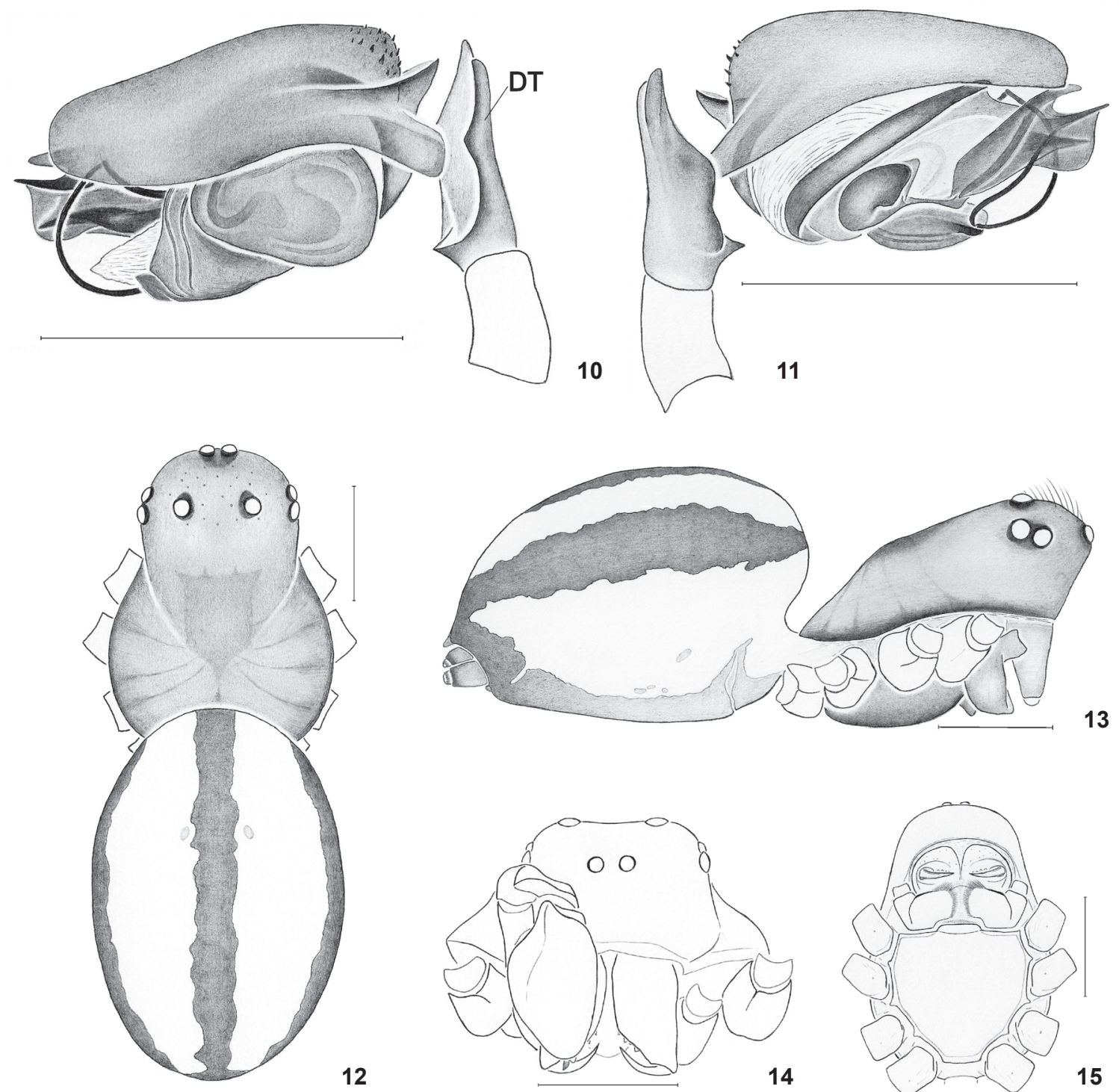

13

12
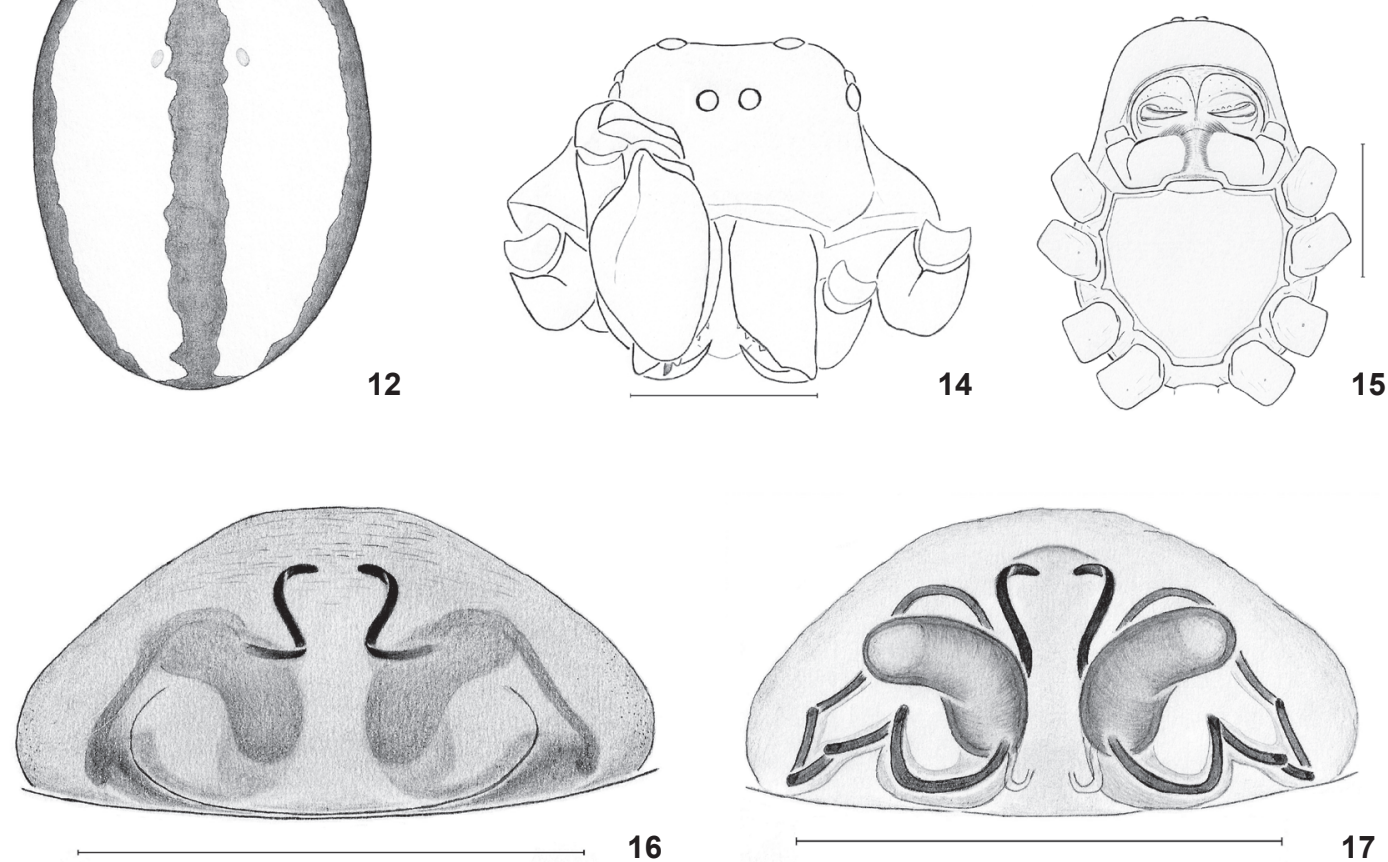

Figures 10-17. Psilocymbium lineatum. (10-11) Male palpus: (10) ectal view, (11) mesal view. (12-15) Male habitus: (12) dorsal view; (13) lateral view; (14) frontal view; (15) ventral view, sternum detail. (16-17) Epyginum: (16) ventral view; (17) dorsal view, cleared. Scale bars: $0,25 \mathrm{~mm}$. 


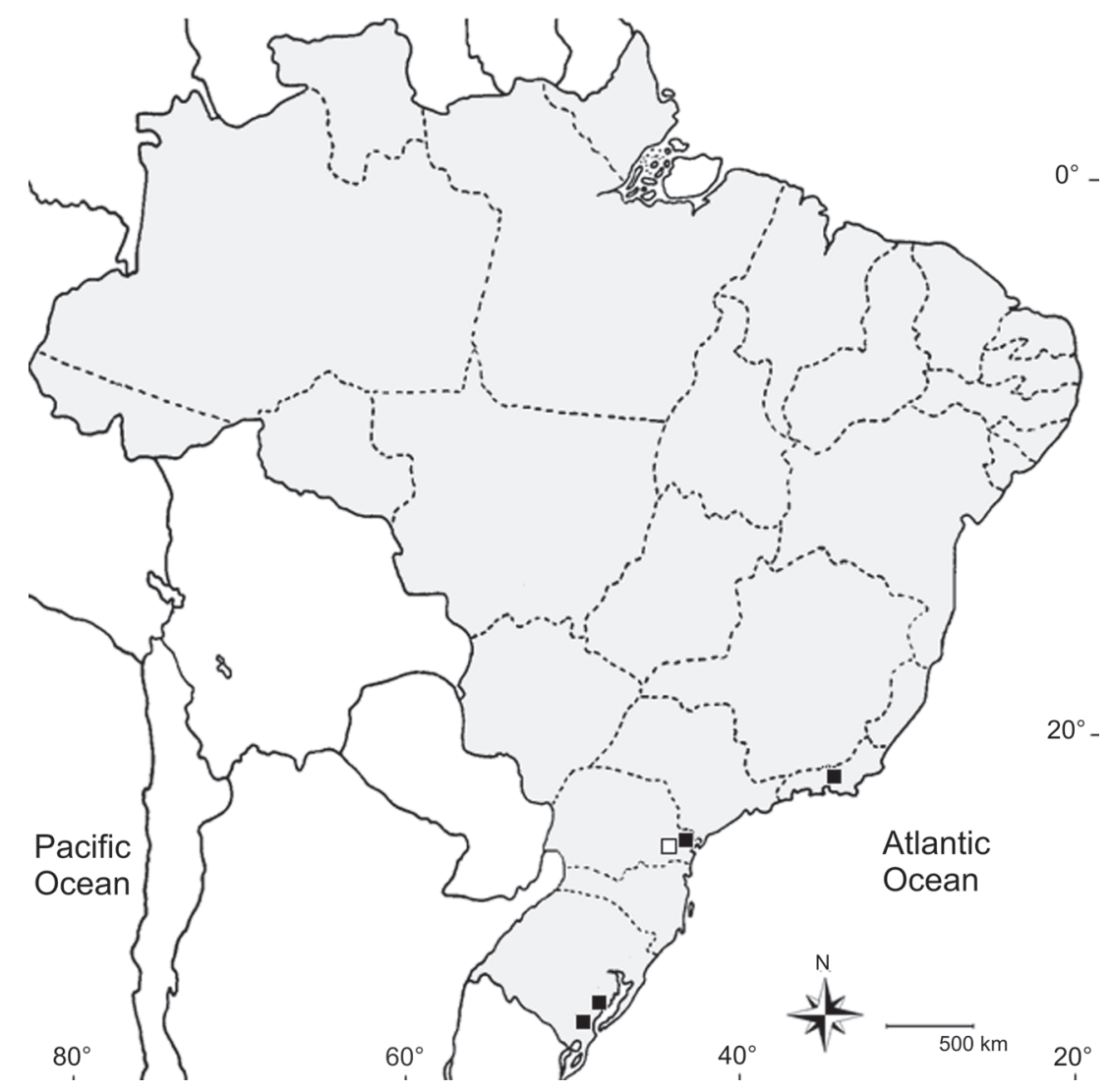

Figure 18. Map showing the distribution of Psilocymbium antonina sp. nov. ( $\square$ ) and P. lineatum ( $\square$ ) in Brazil.

0.42 ; patella $0.16 / 0.13 / 0.11 / 0.13$; tibia $0.31 / 0.32 / 0.22 / 0.35$; metatarsus $0.26 / 0.25 / 0.22 / 0.26$; tarsus $0.27 / 0.26 / 0.23 / 0.25$; total: 1.38/1.34/1.09/1.41. Coxa IV well apart from each other (0.21). Palp (femur, patella, tibia, cymbium): 0.25/0.21/0.13/ 0.28. Tm I 0.64. Metatarsus I-III with trichobothrium, IV absent. The tibial spine formula: 0-0-1-1. Patella I and II with macrosetae distal. Eye diameters and interdistances: AME 0.03, ALE 0.05, PME 0.05, PLE 0.05; AME-ALE 0.12, PME-PLE 0.06, AME-AME 0.02, PME-PME 0.12. Eyes with black borders (Figs 12 and 13). Clypeus not pubescent (Fig. 14). Carapace anteriorly projected (Fig. 15). Cephalotorax brown with dark-brown borders and medial area, projected at cephalic area, pubescent at ocular area, smooth posteriorly. Chelicerae brown. Promargin with four teeth and retromargin with two. Endites brown with dark-brown dots. Sternum brown with dark-brown dots, slightly pubescent, truncated (Fig. 15), wider than long. Coxae yellowish-brown, dark-brown dotted distal borders, III slightly smaller. Legs yellowish-brown. Abdome longer than wide, oval, whitish-yellow with enlarged black medial longitudinal stripe and similar lateral stripes all extending from over the pedicel until spinnerets; whitish-yellow venter with broad pigmented medial area also pigmented around spinnerets, highly pubescent.
Spinnerets brown. Colulus well developed. Palp with long coiled embolus, tegulum with ventral prominence, suprategulum gauged with sharp tip located below cymbium border, tibia dorsally enlarged (Figs 10 and 11).

Female. Described by Miluidge $(1991: 131,132)$ and Miller (2007: 229, 230). Illustrations from specimen MCN 46392 (Figs 16 and 17).

New records. BraziL, Paraná: Guaraqueçaba (Reserva Natural da Serra do Itaqui), 1 female, 18.IX.2007, E.S.S. Álvares leg. (MCN 45679); Rio Grande do Sul: Cristal (Mata ciliar do Rio Camaquã, $\left.31^{\circ} 01^{\prime} 01.7^{\prime \prime} \mathrm{S}, 51^{\circ} 56^{\prime} 42.0^{\prime \prime} \mathrm{W}\right)$, 1 male, 1 female, 19.XII.2007, E.N.L. Rodrigues leg. (MCN 46392), Arroio Grande (Mata ciliar do Rio Piratini, 3154'06.47"S, 52³9'08.29”W), 1 female, 13.VI.2006, E.N.L. Rodrigues leg. (MCN 46393).

Distribution. Brazil (Rio de Janeiro, Paraná and Rio Grande do Sul).

Natural history. Collected from riparian and restinga forests of southern Brazil with a beating tray underneath bush and tree vegetational strata.

Remark. The description and illustrations MilLER (2007) and Millidge (1991) render the examination of the type material of this species unnecessary. 


\section{ACKNOWLEDGEMENTS}

We would like to thank Erica H. Buckup (MCN), for loaning material and providing references, and the director's office of the MCN by providing work space for the senior author. We also thank Antonio D. Brescovit from the Instituto Butantan, São Paulo, for the loan of the stereomicroscope used in this study. We also thank Ludger Scheuermann and Florian Raub (Staatliches Museum für Naturkunde Karlsruhe, Germany) for the donation of Solobioma Project spiders samples. This study was supported by CNPq (process 140586/2007-5 to E.N.L. Rodrigues from Programa de Pós-Graduação em Biologia Animal, Universidade Federal do Rio Grande do Sul).

\section{LITERATURE CITED}

Denis, J. 1949. Notes sur les érigonides. XVI. Essai sur la détermination des femelles d'erigonides. Bulletin de la Société d'Histoire naturelle de Toulouse 83: 129-158.
Hormiga, G. 2000. Higher level phylogenetics of erigonine spiders (Araneae, Linyphiidae, Erigoninae). Smithsonian Contributions to Zoology 609: 1-160.

Miller, J.A. 2007. Review of Erigonine Spider Genera in the Neotropics (Araneae: Linyphiidae, Erigoninae). Zoological Journal of the Linnean Society 149 (Suppl. 1): 1-263.

Millidge A.F. 1991. Further linyphiid spiders (Araneae) from South America. Bulletin of the American Museum of Natural History 205: 1-199.

PlatNICK, N.I. 1993. Advences in Spider Taxonomy 1998-1991. New York, New York Entomological Society \& American Museum of Natural History, 846p.

Platnick, N.I. 2009. The world spider catalog, version 10.0. American Museum of Natural History, available on line at: http://research.amnh.org/entomology/spiders/catalog/ index.html [Acessed: 15/VIII/2009].

RoberTs, M.J. 1987. The spiders of Great Britan and Ireland: Linyphiidae and check list. Colchester, Harley Books, vol. 2, 204p.

Submitted: 11.IX.2009; Accepted: 03.V.2010.

Editorial responsibility: Antonio Domingos Brescovit 